\title{
THE ROLE OF CONSUMER INFLUENCES IN THE NEW PRODUCT DEVELOPMENT OF PACKAGED FOOD AND BEVERAGE VENTURES
}

\author{
Perttunen, Erika Maria (1); \\ Jung, Summer D. (2); \\ Kirjavainen, Senni (1); \\ Björklund, Tua A. (1); \\ Kim, Sohyeong (2) \\ 1: Aalto University; \\ 2: Stanford University
}

\begin{abstract}
Understanding and applying consumers' needs in product development is key to success across various industries. The failure rate of new products, however, remains high because consumer demands are not adequately addressed. To investigate the role of consumers in the product development processes of small ventures, we conducted in-depth, semi-structured interviews of 40 packaged food and beverage small ventures in California and Finland. Our findings showed that consumers rarely drove the design of new products, but rather functioned as a source of validation or feedback for small improvements of existing products. Consumer feedback was often unstructured and concentrated in the latter stages of the product development process. However, even though customer involvement in the small ventures' product development was more restricted than recommended in cocreation literature their influence still brought meaningful changes to the products. Given the small ventures' lack of resources, future research on creative, low-cost ways to co-create is called for.
\end{abstract}

Keywords: New product development, Design process, Participatory design

\section{Contact:}

Perttunen, Erika Maria

Aalto University

Department of Mechanical Engineering

Finland

erika.perttunen@aalto.fi 


\section{INTRODUCTION}

Understanding consumer needs is paramount for successful product development (Linnemann et al., 2006; Grunert and van Trijp, 2014). Yet the failure rates of new products in consumer markets are still high (Castellion and Markham, 2013), and the inability to address consumer demands is a leading cause for the phenomenon (Ryynänen et al., 2014). Facing complex and rapidly changing consumer needs, traditional market research methods with a passive view of consumers as mere buyers no longer suffice (O'Hern and Rindfleisch, 2010; Hoyer et al., 2010).

As a result, the literature has shed light on a new paradigm in which consumers are seen as active cocreators in the new product development (NPD) process (Ind and Coates, 2013). Consumers can generate ideas for products that better fulfil their needs or improve the desirability of existing products (Cui and Wu, 2016; Gassmann et al., 2010). Through co-creation, they can further influence which product elements are to be kept and which are to be omitted (O'Hern and Rindfleisch, 2010). Moreover, as product life cycles decrease and new product failures increase, involving consumers in the product design process can foster greater customer acceptance and, ultimately, customer loyalty (Grunert and van Trijp, 2014). Co-design, which Sanders and Stappers (2008) defined as a specific instance of co-creation in which people not trained in design work together through the design process, further offers an opportunity for companies to provide customized products for consumers while massproducing them (Ulrich et al., 2003). For consumers, the co-design process can not only bring enjoyment but also enhance the attitudinal and behavioral response to the designed products (Yu and Park, 2014). Also, instead of the mass, specific groups of consumers can be invoked as in the case of lead users (von Hippel's, (1989) that are leveraged to grasp future consumer needs.

Despite the reported benefits of consumer co-creation for companies and consumers, such as increased new product creativity, decreased time to market, and reduced development costs (O'Hern and Rindfleisch, 2010), the phenomenon is not yet completely understood. As Filieri (2017) points out, literature largely focuses on the customer relationship management side of co-creation, neglecting the new product development side. Furthermore, only a handful of studies look at the impact of cocreation at the different stages of NPD (Filieri, 2017; Kristensson and Magnusson, 2010). Thus, it is necessary to investigate consumers' impact throughout the whole NPD process.

Another limitation we identified in the current customer involvement and co-creation literature is its heavy focus on large companies. Smaller companies are inherently different from large companies in how they interact with their consumers due to their limited resources, less formalized processes, and less hierarchical organizational structures (Lagrosen, 2005; Hörte et al., 2008; Gilmore et al., 2001). Furthermore, small ventures can have greater pressure for new products to succeed fast due to more limited reserve resources to sustain operations in the face of lacking revenue. Thus, meeting customer needs and expectations is of utmost importance for them (Tardivo et al., 2017; Ngugi et al. 2010).

Among various industries, the food industry provides a particularly intriguing arena for examining customer involvement in small companies' NPD processes. Recently, the industry has undergone numerous societal and technological changes (Bigliardi and Galati, 2013), shifting from supply-based operations to demand-driven ones (Costa and Jongen, 2006). Furthermore, the interconnectivity of the industry adds to the industry players' interest in opening up the innovation process to more stakeholders (Capitanio et al., 2010). Yet, especially small players may find themselves constrained and locked-in due to the power larger players have in food supply chains (Mikkola, 2008). However, the gaps identified in the customer involvement and co-creation literature carry through to the food industry. The field research on the influence of customer involvement in the food and beverage industry is scarce. Within the context of large companies, a few case studies delineate how they involve consumers in their NPD process. For instance, Thomke and von Hippel (2002) explored a case regarding a supplier of flavors for the food industry that involved customers in its product design process. By outsourcing parts of the design process to its consumers, the supplier gained information on consumers' taste preferences. Similarly, consumer-led product development was found to deliver benefits in the kiwi industry (Jaeger et al., 2003) as well as beef and yogurt industries (Grunert and Valli, 2001). However, considering the structural differences between large and small companies, more research is needed on the role of consumers in small food ventures' NPD processes.

One of the few studies addressing this gap concludes that small food and beverage ventures are increasingly aware of the importance and benefits of consumer involvement in the NPD, yet they are rarely able to extend the role of consumers beyond testers (Tardivo et al., 2017). We set out to further 
address this gap by investigating how customers impact the NPD of small ventures in the food industry during different stages of the NPD, based on an analysis of 40 Finnish and Northern Californian food and beverage small ventures.

\section{DATA AND METHODOLOGY}

Our qualitative dataset consists of 59 interviews, 20 from 20 Northern Californian (USA) and 39 from 20 Finnish food and beverage ventures. Each US company was interviewed once, while for the Finnish companies each co-founder was interviewed separately in the case of multiple founders. All companies were recruited by cold-calling or snowball sampling (Biernacki and Waldorf, 1981). The case companies varied in size from one-person startups to small companies, and about three quarters of the companies were micro-sized enterprises (MSEs) with less than 10 employees (Buculescu, 2013). All companies had at least one packaged product in the market. The data was collected through a series of in-depth, semi-structured interviews. The critical incident-based thematic interviews (Flanagan, 1954; Chell, 2004), focused on real anecdotal reports on the companies' NPD activities, including the companies' interactions with different stakeholders, collaborations with other companies, and experiments with consumers. The interviews were conducted face-to-face or via videoconferencing with the founder or other early key personnel. The interviews were audio recorded and transcribed verbatim. Some quotes have been translated into English for presentation purposes. The research process was guided by European Union General Data Protection Regulation and approved by an Institutional Review Board.

Then, the data was analyzed in four stages. First, all mentions of the interviewees' direct interactions with end users were identified. This procedure resulted in 133 mentions in the Northern Californian data and 134 mentions in the Finnish data. In the second phase of analysis, we coded for all instances in which the end users had an impact on the ventures' product development activities. The final step was thematic coding of those instances in which end users influenced the product or package design (Braun and Clarke, 2006), identifying the four types of influences (design influence, validation, new product idea, and design driver). Additionally, three other dimensions were coded to capture the nuances of consumer involvement instances: 1) the intentionality of the influences (intentional and unintentional), 2) the phase of product development in which the influence occurred (predevelopment, product development and testing, and commercialization), and 3) the duration of the influence instances (a one-off, short term instance, a series of short-term instances, and a long-term interaction).

\section{RESULTS}

From the dataset, we identified 188 instances in which consumers influenced the MSEs' NPD processes (111 from Northern California and 77 from Finland). The ventures' frequency of consumer engagement was across a spectrum, ranging from one venture that interviewed over 150 people to shape their beta product to another startup that only occasionally received new flavor requests from customers. Although the companies varied by degree of consumer involvement, every company reported at least one instance of such involvement. The impact of consumer feedback also varied, as some feedback led to the launch of an entirely new product line, while others held no further impact than simply adding a new nutrition label. The variance will be discussed in the following section, but part of it may also be due to the less formalized more flexible NPD processes of MSEs. Furthermore, the majority of the feedback was intentionally solicited by the companies in product demos or taste testings at grocery stores (Finnish MSEs) or farmer's markets (Northern Californian MSEs). Such demos or testing were mostly performed in the later stages of product development. Because the interactions at demos or testing were often conversational, the feedback was collected casually rather than structurally. Although the MSEs sometimes struggled to interpret the unstructured feedback, the qualitative aspect added more depth to the feedback and opened up the opportunity for unexpected findings. For instance, one startup reported, "you always end up getting more information than you expected," explaining how she preferred a phone call to an email. 


\subsection{Type of influence}

The customers had four types of influence on the product development process of the companies: design influences, validation, new product ideas, and design drivers. The design influences and validation mostly took place in the latter part of NPD, from product development/testing to commercialization, while new product ideas and design drivers were provided in the pre-development phase. Table 1. shows the number of instances for each type of influence in the Northern Californian, Finnish and combined data.

Table 1. Type of influence

\begin{tabular}{|lllll|}
\hline TYPE OF INFLUENCE & & \\
\hline DESIGN INFLUENCES & consumer feedback leading to iteration of existing product & 70 & 103 \\
\hline VALIDATION & consumers' endorsement of existing product, not leading to iteration & 20 & 26 & 46 \\
\hline NEW PRODUCT IDEAS & consumers' suggestions for new products & 16 & 11 & 27 \\
\hline DESIGN DRIVERS & consumer input leading to launch of new product line & 5 & 7 \\
\hline
\end{tabular}

\subsubsection{Design influences}

The design influence incidents $(n=103)$ were cases in which consumers affected either the packaging or content of the startups' existing products, leading to iteration of an attribute. The iterations were mostly incremental, such as tweaking a label on a package or the sugar level of a product. In most cases, the iterated product or package was a ready-made prototype that required only final touches or a commercial product. From the Northern Californian dataset, the requested changes reflected the food trends in the market, such as the shift towards the foods that are sustainable, plant-based, and free of Genetically Modified Organisms (GMO). Oftentimes, the startups would host taste testings, organize user panels or run demos to gather feedback from customers. The quote below describes an example of a user panel organized to decide the optimal sweetness level of a product:

"For this product, we organized a user panel including various customers from heavy users to ones that don't really fancy the beverage. Due to our limited resources, the testing lasted only one afternoon, but we still got enough feedback from the blind tests to determine the optimal amount of sugar for the product." (Finnish distillery)

Although grocery stores, farmer's markets and restaurants were the most common venues for such user tests, some more unconventional venues included outdoor areas like parks and beaches, customers' own homes, and dedicated test laboratories. It is worth noting that the Northern Californian dataset had almost twice as many instances of design influences as the Finnish instances. The major difference between the two regions was the prevalence of farmer's markets, food startup incubators, and shared commissary kitchens in Northern California, which could have contributed to the higher number of instances. Besides such physical spaces, social media platforms such as Instagram were also reported as a common channel by which startups would gauge consumers' reaction to new products and receive improvement ideas or modification requests.

Most of the design influences were initiated by the companies, but some came directly from the customers. For instance, customers would have trouble understanding the new products or the packages and as a result reach out to the companies to inquire. Through implementing such feedback, the ventures were able to improve both the desirability and the comprehensibility of their products.

\subsubsection{Validation}

In the validation instances $(n=46)$, the companies tested the desirability of their products or packaging concepts, but the feedback did not necessarily lead to any change in the products. Demos, testing sessions and user community gatherings were the most common ways to seek validation from customers. Validations were also initiated by customers, often in the form of encouraging emails. To compare validation with design influences, the former let companies assess customers' acceptance for a product that was already ready for market, whereas the latter allowed the companies to receive input 
on product attributes that were still under development. For example, a Finnish ice cream venture hosted a tasting session to gauge the market reaction, as captured below:

"First time ever, we were running a tasting session at a supermarket. There were 800 customers visiting the store that day, and 100 of them bought a pint of our ice cream. The store owner was like 'Wow, that was a great success!' but we were still a bit hesitant and thought, 'They just bought out of pity.' However, when the same customers came back the next day to buy more, we started to become convinced." (Finnish ice cream venture)

Some of the products were novel foods and beverages, and the companies had to ensure that there was acceptance from their customers. Thus, they presented these novel products to customers to gauge their initial reactions and learn about the markets' readiness for introducing the product as well as create publicity around the novelties. For instance, a kefir company based in Northern California was heartened to hear words of affirmation from her customers at a farmer's market.

"We get a lot [of positive feedback] especially at the farmers market where we're personally selling, I remember there was one woman... She came every single week with a bunch of kids and she would buy lots of kefir and after like... one month she came and told me, 'well, you know what? because of your product I stopped being sick. My kids have stopped being sick.," (Northern California kefir venture)

\subsubsection{New product ideas}

The customer influences in the category of new product ideas $(n=27)$ concerned novel suggestions from consumers. These ideas were suggestions for new products, new package designs or new flavors. Flavor requests were the most common type among the new product ideas, and for some companies, customers were the main source of inspiration for new flavors. Many quotes highlighted the value of such ideas as they directly reflected customers' needs. When a certain flavor was requested repeatedly, a startup could assume that it would be a successful addition to the product portfolio, as illustrated by the following quote:

"But for this one they've been telling me; everyone always asks for a fig jam.... Um, so I find that we have to do this, we need to make a fig jam, like that's just money sitting on the table." (Northern California jam venture)

\subsubsection{Design drivers}

Design drivers $(n=12)$ were similar to new product ideas, but the consumers' impact was stronger, driving the design of a whole new product or new product line in contrast to only the creation of a new flavor. Unlike design influences, which were iterations of existing products, design drivers led to novel products of unprecedented nature. For instance, a jam company decided to launch a line of vinaigrettes and popsicles to address the plant-based trend and diverge from their existing portfolio of jams. In the Finnish data, these design drivers often came from a community of users, typically early adopters or fans. For example, a Finnish ice cream venture decided to launch a whole line of vegan products after repeated consumer requests. This form of consumer influence, however, was rare in the data. Moreover, in the Northern Californian dataset, half of the instances were regarding the very first line of products, not a new line.

\subsection{Intentionality, phase of product development, and duration of influence}

\subsubsection{Intentionality of influence}

The incidents of consumer influence could be divided into two types of intentionality from the perspective of the MSEs: intentional and unintentional. Unintentional influences happened in unplanned and unorganized interactions with customers, such as spontaneous customer feedback on a product or a package, unexpected ideas from customers, or informal interactions with the user community. Although mostly this spontaneous feedback was welcomed by the ventures, on some occasions, the MSEs were not pleased by such informal feedback due to its subjectivity and ambiguity. For instance, a ginger beer company received a request from its farmer's market customers to create a sugar-free ginger beer for their diet. The founder was initially against the idea but 
eventually decided to launch it. Nevertheless, it is notable that a significant chunk of the consumer input was not solicited by the companies. In the American data set, about two thirds of the influences were intentional and about one third were unintentional, and in the Finnish data set, the respective shares were three fourths and one fourth. We conjecture that the difference came from the wide adoption of farmer's markets in the Northern California region. In fact, a cracker company remarked on how a group of vocal, educated, and health-aware customers in one of their farmer's markets would continuously give them strong feedback.

Intentional influences took place in more organized events like testing sessions, user interviews or user panels. Here, the goal of the companies was to interact with customers to collect feedback, to get ideas for new products, or to get validation for their product concept. Although the companies put a lot of effort arranging such activities, it was difficult for them to actually benefit from the influences because the consumers would give mixed feedback. Furthermore, in the Northern Californian data, some companies had to hire third parties or grocery store partners to handle the demos or testings, thus adding an extra layer of abstraction between the customers and the companies.

Table 2. Intentionality of influence

\begin{tabular}{|c|c|c|c|c|}
\hline ORIGIN OF INFLUENCE & & & & Total \\
\hline INTENTIONAL & feedback solicited by the companies & 69 & 57 & 126 \\
\hline UNINTENTIONAL & feedback unsolicited & 39 & 19 & 58 \\
\hline UNCLEAR INTENTIONALITY OF THE INSTANCE & & 3 & 1 & 4 \\
\hline
\end{tabular}

\subsubsection{Duration of influence}

The durations of the interaction resulting in consumers having an influence on the interviewed companies varied among one-off short-term interactions, a series of short-term interactions and continuous long-term interactions. One-off short-term interactions included instances like an individual testing session or a one-time user panel. When such one-off incidents were repeated in a similar fashion with a different group of customers, they were counted as a series of short-term interactions. In contrast, long-term interactions referred to long-lasting, sometimes bidirectional, interactions with a group of customers.

The majority of the instances fell into either one of the two short-term categories, implying that longlasting engagement with customers was still somewhat rare. Some rare exceptions were a few Finnish ventures' long-term relationships with their user communities. The interactions were not only bidirectional but also casual. In the US data, there was only one startup that managed a relationship with the same community of users. In this case the users were the early crowdfunders, to which the startup would send out surveys to get feedback on their new product ideas. The quotes below exemplify the different durations from short-term one-off, to short-term series and finally long-term:

"I think the first time I did some tasting, I had 20 samples, and people were like, are you crazy, how are we gonna really evaluate 20 different combinations. But actually, that day was when I got this main flavor, which contains this beetroot and blueberry, strawberry. And then I added a little bit of banana for the sweetness." (Finnish fermented drink venture)

"Yes, and so luckily I happened to have a friend who was involved in the food truck..., and so I was able to tag along on his food truck event and sell my ginger beer just to strangers and see what they thought. And it was well received and so I'm like, alright, I think I'm onto something here." (Northern California ginger beer venture)

"Here in our farm store we have grinded some of our rolled oats and there has grown a bit of a fan community around this as-unprocessed-as-possible oats. So it was clear that these grinded rolled oats would be one of our products." (Finnish oat and buckwheat snacks venture) 
Table 3. Duration of influence

DURATION OF INFLUENCE

\begin{tabular}{|lllr}
\hline LONG-TERM & continuous interaction with same group of consumers & 7 & 12 \\
\hline SHORT-TERM, ONE-OFF & one time short interaction with a group of consumers & 24 \\
\hline SHORT-TERM, A SERIES & $\begin{array}{l}\text { multiple short interactions with different groups of } \\
\text { consumers on each interaction }\end{array}$ & 65 \\
\hline UNCLEAR DURATION & & 22 \\
\hline
\end{tabular}

\subsubsection{Phase of product development of influence}

Tracking the phase of product development processes where the influencing incidents took place, the companies' processes were divided into three phases from the initial idea to the market launch: predevelopment, product development and testing, and commercialization. Most of the analyzed influences took place in the last two phases, product development and testing and the commercial launch. This is in line with the most common types of consumer influences, design influences and validation, which usually take place only after the concept development phase of a product. Predevelopment influences were relatively rare, implying that there is still significant potential to benefit from more customer involvement in the front-end phases of product development.

A point worth noting is that no customer influence lasted throughout the whole product development process. Therefore, as stated already in connection with the duration of influence, the interactions between customers and ventures were rather brief and transitory in nature. Customers were used as information sources at specific points in the product development process rather than active co-designers or co-innovators.

Table 4. Phase of product development of influence

\begin{tabular}{|l|l|}
\hline PHASE BEING INFLUENCED & Quote example \\
PRE-DEVELOPMENT & "But for this one they've been telling me, everyone always asks for a \\
fig jam." & -
\end{tabular}

\section{DISCUSSION}

The current study investigated consumer involvement in and influences on the NPD of Finnish and North Californian food and beverage ventures. While consumers were involved in various ways in different phases of the companies' product development process, in most cases, their influence only led to small improvements of existing products or validated the concepts under development. The companies also engaged their consumers mostly in the latter phases of product development, missing the benefits of early user involvement (Gruner and Homburg, 2000; Hoyer et al., 2010), such as avoiding expenses after product launch, reducing failure or avoiding a locked-in position in a supply 
chain (Hoyer et al., 2010). Furthermore, consumers were never engaged throughout the whole NPD process. In their case studies of three Italian food small ventures, Tardivo et al. (2017) found that consumers were involved in the latter NPD stages, merely playing the role of co-testers. Similarly, our data show that the food MSEs practices were rarely aligned with the higher intensity co-creation that literature advises.

The two approaches for co-creation in the literature, participatory design and human-centred design, both advocate for continuous and bidirectional consumer involvement starting early on in the NPD (Abras et al., 2004; Ind and Coates, 2013). Our empirical data, however, show that the consumer involvement was sporadic, mostly consisting of fleeting encounters with different groups of consumers. The consumers would casually provide new flavor ideas but only rarely drove the design of entirely new products. Consumers rarely played the more involved roles of co-designers or coinnovators.

A few factors contributed to such practices. First, the entrepreneurs reported difficulties in interpreting and applying the typically subjective and ambiguous input from consumers. Second, harvesting feedback from consumers was seen to require many resources, including time, labour, and money. For instance, some of the Northern Californian startups hired a third party or grocery store partner to run demos on their behalf. Such a process introduced an extra layer of abstraction,making the feedback more difficult to digest. The lack of direct contact can also lessen consumers' understanding of the company, which is one of the benefits of engaging with consumers (Vivek et al., 2012). Third, the venues the ventures used, such as a farmer's market or grocery store, were not optimal for structured feedback gathering. Traditional design research methods like user interviews or market research techniques like focus groups, which could provide more structured feedback, were scarce in the results. These factors point to companies lacking capabilities and resources for co-creation (Lagrosen, 2005). Setting up the processes for engaging customers as co-designers or co-innovators in the NPD can require ample resources, which MSEs often lack (Hörte et al., 2008).

In fact, such a resource disadvantage has to be taken into account in the assessment of the ventures' practices. Although the ways companies engaged with their consumers were not typically aligned with the ideals of co-creation, the consumers were not ignored by any means. It is notable that the consumers were able to bring about significant changes in the products, even in the latter stages of the NPD. Perhaps such practices were only possible because the companies were small and their NPD processes are generally more fluid and less structured than those of larger companies (Nicholas et al., 2011). Considering the companies' constraints on resources, receiving sporadic, unstructured, and even unsolicited feedback might have actually been a good strategy for engaging their customers as less formalized NPD may render it difficult to engage customers throughout the whole process. Thus, it is impossible to set the ways of customer involvement in any clear order of quality. It rather seems that the ventures were involving their customers in ways most accessible and beneficial for them.

The findings call for more research on small ventures consumer involvement. Most importantly, cocreation strategies suitable for small ventures of different degrees of capabilities and resources should be devised. Large corporations' strategies to engage consumers in earlier product development stages should be assessed to determine their applicability to small ventures. Small ventures that are effectively overcoming the low-resource environment and incorporating consumer feedback into their NPD can act as case studies for showing how smaller organizations can leverage co-creation, and further research on creative and low-cost methods to gather consumer insights or to encourage reciprocal involvement is called for (Ind and Coates, 2013). Further research is also needed to measure the economic impact of the different types of consumer influence, particularly in longitudinal studies to avoid selection bias. Lastly, the findings of the current study may not be generalized to other regions or other industries, and further research is needed to evaluate the representativeness of the current results.

\section{CONCLUSION}

This study contributes to new product development and co-creation literature through highlighting the ad hoc nature of most consumer involvement in the new product development efforts of food and beverage MSEs. Rather than systematic, high-intensity involvement such as in co-creation, the majority of the consumer influences took place in the later stages of the NPD and came from short- 
term interactions with varying groups of consumers. However, these influences were meaningful and resulted in even large changes, potentially due to the more flexible development processes of the MSEs than what would be typical in larger organizations. Co-creation, in the way it is currently advised, can require significant capabilities and resources from both the companies and the consumers. Thus, future research should explore ways for MSEs to expand their current practices of consumer involvement to the earlier stages of NPD while keeping costs low. Furthermore, the dynamics and different forms of co-creation should be assessed within more heterogeneous contexts, including the non-technological industries and smaller ventures that often have a systemized NPD process.

\section{REFERENCES}

Abras, C., Maloney-Krichmar, D., Preece, J. (2004). “User-centered design.” Bainbridge, W. Encyclopedia of Human-Computer Interaction. Thousand Oaks: Sage Publications, 37(4), 445-456. http://aim.johnkeston.com/wp-content/uploads/2012/01/User-centered_design_encyclopedia_chapter.pdf

Biernacki, P., Waldorf, D. (1981). "Snowball sampling: Problems and techniques of chain referral sampling." Sociological methods \& research, 10(2), 141-163. https://doi.org/10.1177/004912418101000205

Braun, V., Clarke, V. (2006). "Using thematic analysis in psychology." Qualitative research in psychology, 3(2), 77-101. https://doi.org/10.1191/1478088706qp063oa

Bigliardi, B., Galati, F. (2013). "Models of adoption of open innovation within the food industry." Trends in Food Science \& Technology, 30(1), 16-26. https://doi.org/10.1016/j.tifs.2012.11.001

Buculescu, M.M. (2013). "Harmonization process in defining small and medium-sized enterprises. Arguments for a quantitative definition versus a qualitative one." Theoretical and Applied Economics, 9(586), 103-114. http://store.ectap.ro/articole/905.pdf

Capitanio, F., Coppola, A., Pascucci, S. (2010). "Product and process innovation in the Italian food industry." Agribusiness, 26(4), 503-518. https://doi.org/10.1002/agr.20239

Castellion, G., S. K. Markham. (2013). "Perspective: New Product Failure Rates: Influence of Argumentum ad Populum and Self-Interest." Journal of Product Innovation Management, 30(5), 976-979. https://doi.org/10.1111/j.1540-5885.2012.01009.x

Chell, E. (2004). "Critical incident technique." In Cassell, C. Symon, G. (ed.) Essential guide to qualitative methods in organizational research. Gateshead: SAGE Publications. p.45-60. https://doi.org/10.4135/9781446280119.n5

Costa, A. I., Jongen, W. M. F. (2006). "New insights into consumer-led food product development." Trends in Food Science \& Technology, 17(8), 457-465. https://doi.org/10.1016/j.tifs.2006.02.003

Cui, A. S., Wu, F. (2016). "Utilizing customer knowledge in innovation: antecedents and impact of customer involvement on new product performance." Journal of the academy of marketing science, 44(4), 516-538. https://doi.org/10.1007/s11747-015-0433-x

Flanagan, J.C. (1954). “The critical incident technique." Psychological Bulletin, 51(4), p. 327-58. https://doi.org/10.1037/h0061470

Gassmann, O., Enkel, E., Chesbrough, H. (2010). “The future of open innovation.” R\&D Management, 40(3), 213-221. https://doi.org/10.1111/j.1467-9310.2010.00605.x

Gilmore, A., Carson, D., Grant, K. (2001). "SME marketing in practice.” Marketing intelligence \& planning. https://doi.org/10.1108/02634500110363583

Gruner, K. E., Homburg, C. (2000). “Does customer interaction enhance new product success?”. Journal of business research, 49(1), 1-14. https://doi.org/10.1016/s0148-2963(99)00013-2

Grunert, K. G., Valli, C. (2001). "Designer-made meat and dairy products: consumer-led product development." Livestock Production Science, 72(1-2), 83-98. https://doi.org/10.1016/s0301-6226(01)00269-x

Grunert, K. G., van Trijp, H. C. (2014). "Consumer-oriented new product development." Encyclopedia of agriculture and food systems, 2, 375-386. https://doi.org/10.1016/b978-0-444-52512-3.00062-0

Hoyer, W. D., Chandy, R., Dorotic, M., Krafft, M., Singh, S. S. (2010). "Consumer cocreation in new product development." Journal of service research, 13(3), 283-296. https://doi.org/10.1177/1094670510375604

Hörte, S. Å., Barth, H., Chibba, A., Florén, H., Frishammar, J., Halila, F., ... Tell, J. (2008). "Product development in SMEs: a literature review." International Journal of Technology Intelligence and Planning (IJTIP), 4(3), 299-325. https://doi.org/10.1504/ijtip.2008.020099

Ind, N., Coates, N. (2013). "The meanings of co-creation." European Business Review. https://doi.org/10.1108/09555341311287754

Jaeger, S. R., Rossiter, K. L., Wismer, W. V., Harker, F. R. (2003). "Consumer-driven product development in the kiwifruit industry." Food quality and preference, 14(3), 187-198. https://doi.org/10.1016/s09503293(02)00053-8 
Kristensson, P. Magnusson, P.R. (2010). “Tuning users' innovativeness during ideation.” Creativity and Innovation Management, 19(2), pp. 147-59. https://doi.org/10.1111/j.1467-8691.2010.00552.x

Lagrosen, S. (2005). "Customer involvement in new product development." European Journal of Innovation Management. https://doi.org/10.1108/14601060510627803

Linnemann, A. R., Benner, M., Verkerk, R., van Boekel, M. A. (2006). "Consumer-driven food product development." Trends in Food Science \& Technology, 17(4), 184-190. https://doi.org/10.1016/j.tifs.2005.11.015

Mikkola, M. (2008). "Coordinative structures and development of food supply chains." British Food Journal. https://doi.org/10.1108/00070700810849907

Ngugi, I. K., Johnsen, R. E., Erdélyi, P. (2010). "Relational capabilities for value co-creation and innovation in SMEs." Journal of small business and enterprise development. https://doi.org/10.1108/14626001011041256

Nicholas, J., Ledwith, A., Perks, H. (2011). "New product development best practice in SME and large organisations: theory vs practice.” European Journal of Innovation Management. https://doi.org/10.1108/14601061111124902

O’Hern, M. S., Rindfleisch, A. (2010). “Customer co-creation: a typology and research agenda.” Review of marketing research, 6(1), 84-106. https://doi.org/10.4324/9781315088754-4

Ryynänen, T., Hakatie, A. (2014). 'We must have the wrong consumers'-a case study on new food product development failure.” British Food Journal. https://doi.org/10.1108/bfj-08-2012-0215

Sanders, E.B.N., Stappers, P.J. (2008). "Co-creation and the new landscapes of design.” Co-design, 4(1), 5-18. https://doi.org/10.1080/15710880701875068

Tardivo, G., Thrassou, A., Viassone, M., and Serravalle, F. (2017). "Value co-creation in the beverage and food industry." British Food Journal. https://doi.org/10.1108/bfj-02-2017-0119

Thomke, S., Von Hippel, E. (2002). "Customers as innovators: a new way to create value.” Harvard business review, 80(4), 74-85. https://doi.org/10.1080/08956308.2020.1733887

Ulrich, P.V., Anderson-Connell, L.J., Wu, W. (2003). "Consumer co-design of apparel for mass customization." Journal of Fashion Marketing and Management: An International Journal. https://doi.org/10.1108/13612020310496985

Vivek, S. D., Beatty, S. E., Morgan, R. M. (2012). "Customer engagement: Exploring customer relationships beyond purchase." Journal of marketing theory and practice, 20(2), 122-146. https://doi.org/10.2753/mtp1069-6679200201

Yu, U.J., Park, J. (2014). “Consumers' Virtual Product Experiences and Risk Perceptions of Product Performance in the Online Co-Design Practice: A Case of NIKEiD." Family and Consumer Sciences Research Journal, 43(1), 29-46. https://doi.org/10.1111/fcsr.12079

Von Hippel, E. (1986). "Lead users: a source of novel product concepts.” Management science, 32(7), 791-805. https://doi.org/10.1016/0737-6782(87)90069-5 